INDO GLOBAL JOURNAL OF

PHARMACEUTICAL SCIENCES

ISSN 2249- 1023

\title{
Quality Assessment of Tea Leaf Grains Based on Image Analysis
}

\author{
Aastha Juneja, Neeraj Wadhwa* \\ Department of Biotechnology, Jaypee Institute of Information Technology, Noida, Uttar Pradesh, India
}

Address for Correspondance: Neeraj Wadhwa, neeraj.wadhwa@jiit.ac.in

Keywords Indian

Tea; Image

Analysis; Grading.
ABSTRACT: Computer vision has the potential to become a vital component of automated food processing operations by which the automated, rapid and hygienic inspection of diverse raw and processed foods can be achieved with minimal errors.Various physical properties measurement e.g. size, shape, color composition, texture of the particles of choice can be studied via Image analysis. This process involves distinguishing of the objects (regions of interest) from the background and producing quantitative information, which is used in the subsequent control systems for decision making. Decisions regarding the success of a particular brand of tea mix in a market depend on the quality assessment of the fermented tea leaf grains followed by Sensory evaluation of the fermented tea leaf grains used in the mix. It is well documented that under-fermentation and over- fermentation may make a difference to the quality of standard and it is well known that that tea granule size dependency shows a correlation with fermentation. Standard sensory evaluation of the tea involves the method which consists in extracting of soluble substances in dried tea leaf and then the tasters grade the tea based on taste, colour as well as aroma. There is a need of recognition and classification and automatic detection and recognition and grading for various tea mix. In this study, the webcam of 8 megapixel is used to acquire the image database for various local Indian tea for example Shahinoor ,Special, Premium, Anmol, Export quality and shape feature and texture features were extracted which were then correlated to consumer preference grading classification. (C) 2016 iGlobal Research and Publishing Foundation. All rights reserved.

Conference Proceedings: International Conference on Advances in Plant and Microbial Biotechnology (PMB2017); JIIT, Noida: February 02-04, 2017

Indo Global Journal of Pharmaceutical Sciences( ISSN 22491023 ; CODEN- IGJPAI; NLM ID: 101610675) indexed and abstracted in EMBASE(Elsevier), SCIRUS(Elsevier),CABI, CAB Abstracts, Chemical Abstract Services(CAS), American Chemical Society(ACS), Index Copernicus, EBSCO, DOAJ, Google Scholar and many more. For further details, visit http://iglobaljournal.com 